\title{
Aplicação aérea de grânulos de argila como veículo de herbicidas para o controle de plantas daninhas em área de reforma de eucalipto ${ }^{1}$
}

\author{
Aerial application of herbicides in clay granules to weed control in Eucalyptus
}

\author{
Caio Antonio Carbonari ${ }^{2}$, Edivaldo Domingues Velini ${ }^{3}$, Giovanna Larissa Gimenes Cotrick \\ Gomes ${ }^{4}$, Ernesto Norio Takahashi ${ }^{5}$, Sergio Ricardo Portes Bentivenha ${ }^{6}$
}

\begin{abstract}
Resumo - Foi realizado um experimento, em uma área de reforma da cultura do eucalipto, no município de Capão Bonito, SP, Brasil, com o objetivo de avaliar a eficácia da aplicação aérea de grânulos de argila como veículo dos herbicidas sulfentrazone e isoxaflutole, no controle de plantas daninhas em uma área de reforma de eucalipto. Foi realizada aplicação aérea dos herbicidas sulfentrazone, nas doses de 500 e $750 \mathrm{~g} \mathrm{ha}^{-1}$ e isoxaflutole, nas doses 150 e $225 \mathrm{~g} \mathrm{ha}^{-1}$, utilizando-se como veículo grânulos de argila com densidade de $1,05 \mathrm{~g} \mathrm{~cm}^{-3}$, alta capacidade de absorção ( $24 \mathrm{~mL} 100 \mathrm{~g}^{-1}$ ), alta resistência ao desgaste e tamanho das partículas entre 500 microns e $1 \mathrm{~mm}$. Também foram realizadas aplicações dos mesmos produtos e doses com um pulverizador convencional de calda líquida, acoplado a um trator. Além destes tratamentos foi mantida uma parcela testemunha sem aplicação dos herbicidas. Nas parcelas experimentais foram semeadas as espécies Brachiaria decumbens, Ipomoea grandifolia, Merremia cissoides e Panicum maximum, sendo realizadas avaliações visuais de controle aos 75 e 110 dias após aplicação. Foram observados baixos níveis de controle para os dois herbicidas testados na menor dose. O sulfentrazone na dose $750 \mathrm{~g} \mathrm{ha}^{-1}$ apresentou melhores resultados no controle de $B$. decumbens e $P$. maximum para a aplicação sólida e resultados similares para as duas modalidades de aplicação para as demais espécies de plantas daninhas. O isoxaflutole na dose de $215 \mathrm{~g} \mathrm{ha}^{-1}$ apresentou inicialmente resultados melhores para aplicação convencional e ao final do experimento níveis similares ou maiores para aplicação na formulação sólida, em relação à aplicação convencional, indicando um aumento no período residual do herbicida.
\end{abstract}

Palavras-Chave: Eucalyptus spp, isoxaflutole, sulfentrazone, tecnologia de aplicação

Abstract - An experiment was carried out in the eucalyptus area of Capão Bonito in the São Paulo state, Brazil, to evaluated the efficacy of the aerial application of the herbicides sulfentrazone and isoxaflutole using clay granules for weed control in Eucalyptus area. Aerial application of the herbicides sulfentrazone at 500 and $750 \mathrm{~g}$ a.i. ha ${ }^{-1}$ and isoxaflutole at 150 e 225

\footnotetext{
${ }^{1}$ Recebido para publicação em 22/07/2011 e aceito em 10/10/2011.

2 Doutor - Dep. de Produção Vegetal, Faculdade de Ciências Agronômicas - FCA/UNESP, Caixa postal 237, 18603 970, Botucatu-SP.

${ }^{3}$ Professor Livre-docente, Dep. de Produção Vegetal, Faculdade de Ciências Agronômicas - FCA/UNESP, Caixa postal 237, 18603-970, Botucatu-SP.

${ }^{4}$ Engenheira Agrônoma, Aluna de Doutorado em Agronomia da Faculdade de Ciências Agronômicas FCA/UNESP, Caixa postal 237, 18603-970, Botucatu-SP.

${ }^{5}$ Engenheiro Florestal, M.Sc., Pesquisador Florestal da FIBRIA, Rod. MS395, Cx. Postal 515, Três Lagoas-MS.

${ }^{6}$ Engenheiro Florestal, M.Sc., Gerente de Tecnologia Florestal da Suzano Papel e Celulose, Av. Dr José Lembo, 1010, Jd Bela Vista, Itapetininga-SP
} 
g a.i. ha ${ }^{-1}$, was carried out using clay granules with $1,05 \mathrm{~g} \mathrm{~cm}^{-3}$ density, high absorption capacity

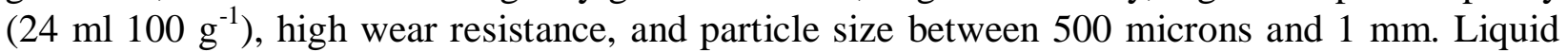
spraying was also performed using the same herbicides at the same doses. A check plot without herbicide application was also used. Brachiaria decumbens, Ipomoea grandifolia, Merremia cissoides e Panicum maximum were sown in the experimental plot, and control evaluations being conducted at 75 and 110 days after application. A low level control was observed for both herbicides at lower doses. Sulfentrazone at $750 \mathrm{~g}$ a.i. ha ${ }^{-1}$ showed better control of $B$. decumbens and $P$. maximum for the aerial application of clay granules and similar results to both applications techniques on other weeds tested. The isoxaflutole at $215 \mathrm{~g}$ a.i. $\mathrm{ha}^{-1}$ showed superior weed control for liquid spraying at the beginning and similar and superior results for the aerial application in the final evaluation, indicating an extension of residual effect of herbicide.

Key-words: Eucalyptus spp, isoxaflutole, sulfentrazone, application technology

\section{Introdução}

O Eucalipto é uma das espécies florestais mais plantadas no mundo, devido suas características de adaptação às diferentes condições climáticas e de solo, e pelo uso diversificado de sua madeira (Mora \& Garcia, 2000). A cultura eucalipto, além do seu importante papel na economia do país, é promissora no que se diz respeito ao fornecimento de energia renovável, recuperação de áreas degradadas e contribuição para o sequiestro de $\mathrm{CO}_{2}$ (Olivette et al., 2011). Em 2010, a área ocupada por plantios de eucalipto totalizou 4.754 .334 ha, sendo que $55,8 \%$ estão localizados na região sudeste, com $22 \%$ no estado de São Paulo (ABRAF, 2011).

A presença de plantas daninhas, principalmente na fase inicial de desenvolvimento do eucalipto, é extremamente prejudicial, sendo inevitável o uso de herbicidas para que não ocorram significativas perdas de produtividade. Segundo Tuffi Santos et al. (2006), as plantas daninhas estão entre os principais problemas na cultura do eucalipto, pelo seu elevado custo de controle, grande demanda de mão-de-obra, impacto do controle químico no ambiente e, consequentemente, redução de produtividade.
O controle químico das plantas daninhas é um método bastante empregado, pois permite resultados mais rápidos, eficientes e mais prolongados. Permite, ainda, o controle da comunidade infestante antes ou depois de sua emergência. Poucos são os herbicidas registrados para o eucalipto, e dentre eles estão o sulfentrazone e o isoxaflutole, que são aplicados em pré-emergência das plantas daninhas, e pertencentes ao grupo dos inibidores da Protox (protoporfirinogênio IX oxidase) e da síntese de carotenóides, respectivamente. A aplicação do sulfentrazone deve ser realizada antes ou após o plantio das mudas, em faixa sobre a linha de plantio, através de jato dirigido, evitando o contato com a parte aérea das plantas, para que não ocorra fitointoxicação. Já o isoxaflutole é um herbicida que não ocasiona injúria nas plantas, ou seja, apresenta boa seletividade à cultura, conforme resultado exposto por Agostinetto et al. (2010).

Devido às dificuldades operacionais na cultura do eucalipto em função da presença de resíduos vegetais sobre o solo, especialmente em áreas de reforma da cultura, com os resíduos remanescentes da colheita, a aplicação de herbicidas impregnados em grânulos de argila de alta densidade pode ser uma alternativa para o controle de plantas daninhas nestas condições. Os grânulos podem ser 
aplicados por meio de aviões, e atravessam os restos vegetais atingindo o solo e liberando o ingrediente ativo. A utilização de formulações granuladas permite ainda que as aplicações dos herbicidas em pré-emergência sejam realizadas após o plantio das mudas, com maior segurança para a cultura, conforme testado por Turnbull et al. (1994). Deve ser destacado que o uso de grânulos elimina o risco da ocorrência da deriva no momento da aplicação, contribuindo, para aumentar a eficácia dos herbicidas e reduzir riscos ambientais.

Diante do exposto, o objetivo deste trabalho foi avaliar a eficácia da utilização de grânulos de argila como veículo para aplicação aérea dos herbicidas sulfentrazone e isoxaflutole, no controle de plantas daninhas em área de reforma na cultura do eucalipto.

\section{Material e métodos}

$\mathrm{O}$ experimento foi instalado em área de reforma de eucalipto na Fazenda Santa Inês, localizada no municipio de Capão Bonito/SP, com predominância de LATOSSOLO VERMELHO dístrofico, de textura argilosa e relevo plano a suave ondulado. As mudas de eucalipto plantadas na área foram do clone VR3709H, plantado com espaçamento de 3,0 x $2,0 \mathrm{~m}$. As parcelas experimentais foram dispostas em faixas para viabilizar a aplicação aérea. Foram utilizadas faixas de $60 \mathrm{~m}$ de largura e $200 \mathrm{~m}$ de comprimento, com corredores de aproximadamente $20 \mathrm{~m}$ entre as faixas, totalizando área útil de 1,2 ha para cada faixa.

Nas faixas, em áreas de 1,0 $\mathrm{m}^{2}$ (repetições) foram incorporadas sementes das plantas daninhas Brachiaria decumbens, Ipomoea grandifolia, Merremia cissoides e Panicum maximum na camada de $0-10 \mathrm{~cm}$, permitindo a germinação das plantas em diferentes profundidades. A quantidade de semente das plantas daninhas foi definida por teste de germinação prévio, mantendo-se aproximadamente 100 sementes viáveis por espécie. Em cada faixa de aplicação foram semeadas oito parcelas (repetições), com cada uma das espécies de plantas daninhas.

No Núcleo de Pesquisas Avançadas em Matologia (NUPAM), da Faculdade de Ciências Agronômicas - UNESP, Botucatu, SP, foi realizada a impregnação dos grânulos de argila com os herbicidas para aplicação aérea. Foram utilizados os herbicidas sulfentrazone $\left(\right.$ Solara $\left.^{\circledR}\right)$, nas doses de 500 e 750 $\mathrm{g} \mathrm{ha}^{-1} \mathrm{e}$ isoxaflutole (Fordor ${ }^{\circledR}$ ), nas doses $150 \mathrm{e}$ $225 \mathrm{~g} \mathrm{ha}^{-1}$, utilizando-se grânulos de argila com densidade de $1,05 \mathrm{~g} \mathrm{~cm}^{-3}$, alta capacidade de absorção $\left(24 \mathrm{~mL} 100 \mathrm{~g}^{-1}\right)$, alta resistência ao desgaste e tamanho das partículas entre 500 microns e $1 \mathrm{~mm}$. Por meio de um misturador, com capacidade de $50 \mathrm{~kg}$ de grânulos, foi realizada a adição e homogeneização dos herbicidas às partículas sólidas.

A quantidade de grânulos utilizada para veicular os herbicidas foi de $40 \mathrm{~kg} \mathrm{ha}^{-1}$, onde foram impregnados os diferentes produtos nas suas respectivas doses. Para as aplicações aéreas foi utilizada uma aeronave agrícola modelo Piper Pawnee PA-25/235 equipada com um aplicador de sólidos, modelo swathmaster. A faixa de deposição efetiva para este ensaio foi de $15 \mathrm{~m}$ e a velocidade de operação foi de $170 \mathrm{~km} \mathrm{~h}^{-1}$.

Para efeito de comparação da eficácia entre as modalidades de aplicação, os mesmos herbicidas e doses foram aplicados por meio de pulverizadores convencionais de barra, com calda líquida, utilizando-se água como veículo para aplicação. As aplicações convencionais dos herbicidas foram feitas com pulverizador acoplado a um trator, com barra constituída por nove pontas de pulverização do tipo TF 2, espaçadas em $1 \mathrm{~m}$, deslocando-se a uma velocidade de $4,2 \mathrm{~km} \mathrm{~h}^{-1}$ e consumo de calda de $211 \mathrm{~L} \mathrm{ha}^{-1}$. Durante as aplicações as condições metereológicas foram: temperatura 
de $30^{\circ} \mathrm{C}, 51 \%$ umidade do ar e ventos entre $2 \mathrm{e}$ $7 \mathrm{~km} \mathrm{~h}^{-1}$. A aplicação aérea e terrestre foi realizada no dia 11 de fevereiro de 2007.

Após as aplicações foram realizadas avaliações visuais de controle, atribuindo-se notas percentuais, onde, "0" corresponde a nenhum controle e "100" ao controle total das plantas (SBCPD, 1995). As notas foram atribuídas aos 75 e 110 dias após a aplicação (DAA), para as plantas daninhas semeadas e as plantas daninhas que ocorreram naturalmente na área. As condições pluviométricas durante o período do experimento estão apresentadas na Tabela 1.

Os resultados de controle das plantas daninhas foram analisados estabelecendo-se o intervalo de confiança pelo teste t a $10 \%$ de probabilidade. Para determinar o intervalo de confiança, foi utilizada a seguinte equação: IC $=(\mathrm{t} x$ desvpad $) / \mathrm{raiz} \mathrm{nr}$, onde, $\mathrm{IC}=$ intervalo de confiança; $\mathrm{t}=$ valor de $\mathrm{t}$ tabelado, ao nível de $10 \%$ de probabilidade; desvpad $=$ desvio padrão e raiz $\mathrm{nr}=$ raiz quadrada do número de repetições.

Tabela 1. Dados pluviométricos ( $\mathrm{mm}$ de chuva mensal) da área experimental durante todo o período de avaliaçào dos experimentos. Capão Bonito/SP - 2007.

\begin{tabular}{cc}
\hline \multicolumn{2}{c}{ Dados Pluviométricos } \\
\hline Mês & Precipitação $(\mathrm{mm})$ \\
\hline Fevereiro & 117,8 \\
\hline Março & 94,8 \\
\hline Abril & 96,4 \\
\hline Maio & 50,5 \\
\hline Junho & 18,5 \\
\hline
\end{tabular}

\section{Resultados e discussão}

Após a aplicação dos herbicidas nas duas modalidades avaliadas ocorreram altos volumes de chuvas. Este fato apresenta grande importância para os resultados observados para aplicação via grânulos, uma vez que esta modalidade de aplicação depende da precipitação para que o ingrediente ativo dos herbicidas seja liberado ao solo (Tabela 1).

Na Figura 1 e 2 estão apresentados os resultados de controle das plantas daninhas pelo herbicida sulfentrazone nas doses de $500 \mathrm{e}$ $750 \mathrm{~g} \mathrm{ha}^{-1}$, respectivamente, através da aplicação aérea e pulverizador convencional.
Para B. decumbens, verifica-se aos 75 DAA e 110 DAA, independente da dose e modalidade de aplicação utilizada, baixos níveis de controle das plantas daninhas. $\mathrm{Na}$ maior dose $\left(750 \mathrm{~g} \mathrm{ha}^{-1}\right)$, embora verificou-se níveis insatisfatórios de controle, destaca-se um maior controle para formulação granulada em relação à aplicação convencional.

Quanto ao controle das plantas de $P$. maximum, observam-se para a dose de $500 \mathrm{~g}$ ha $^{-1}$ (Figura 1), níveis insatisfatórios de controle para ambas as modalidades de aplicação independente do período de avaliação. Na dose de $750 \mathrm{~g} \mathrm{ha}^{-1}$ (Figura 2), foram observados níveis intermediários de 
controle (> 80\%), para a aplicação aérea aos 75 DAA e níveis insatisfatórios para a aplicação convencional.

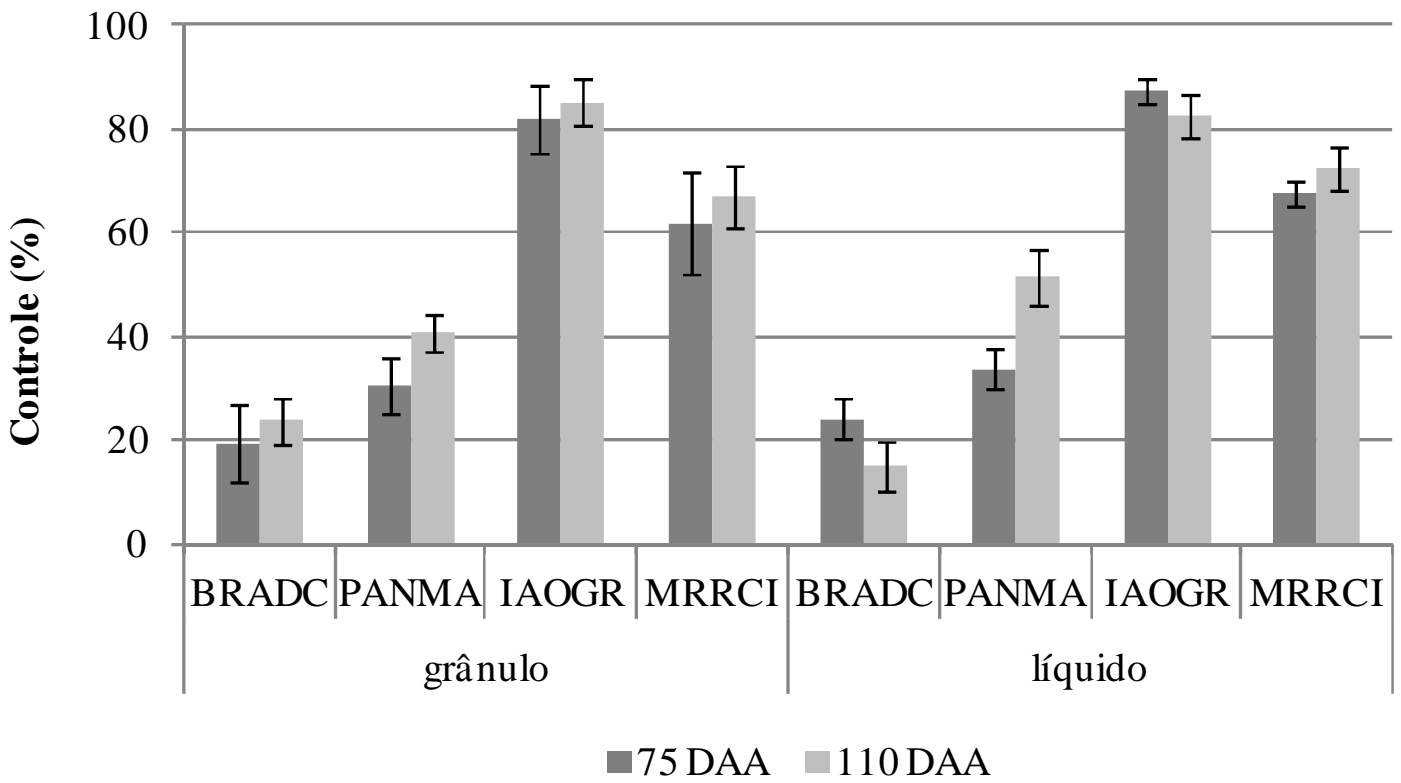

Figura 1. Controle de Brachiaria decumbens (BRADC), Panicum maximum (PANMA), Ipomoea grandifolia (IOAGR) e Merremia cissoides (MRRCI), pelo herbicida sulfentrazone a $500 \mathrm{~g} \mathrm{ha}^{-1}$ aplicado via grânulos por avião e com calda liquida por pulverizador de barras em eucalipto aos 75 e 110 DAA. Capão Bonito/SP - 2007.

O método de impregnação possivelmente permite que o sulfentrazone seja armazenado no grânulo de argila, sendo liberado mais lentamente com a ocorrência de chuvas. O sulfentrazone apresenta solubilidade em água de $490 \mathrm{mg} \mathrm{L}^{-1}$ e pressão de vapor de $1 \times 10^{-9} \mathrm{~mm} \mathrm{Hg}$ a $25^{\circ} \mathrm{C}$. No solo, a mobilidade é moderada, com baixa adsorção e meia-vida de 180 dias (FMC, 1997; Rodrigues \& Almeida, 2005). Essas características permitem que o produto seja veiculado nos grânulos, sendo liberado para o solo com facilidade devido à boa solubilidade e mobilidade. Uma vez no solo, seu espectro de controle e período residual são amplos, garantindo um bom controle das plantas daninhas.
$\mathrm{Na}$ aplicação convencional, a quantidade inicial do sulfentrazone que atingiu o solo no momento da aplicação foi maior, tornando o produto mais susceptível às perdas por lixiviação. Para I. grandifolia, a dose de $500 \mathrm{~g} \mathrm{ha}^{-1}$ (Figura 1) proporcionou níveis adequados de controle (> 80\%), nas duas modalidades de aplicação testadas e nos dois períodos de avaliação. Também para $M$. cissoides a dose de $500 \mathrm{~g} \mathrm{ha}^{-1}$ promoveu resultados semelhantes nas duas formas de aplicação. Mesmo aos 110 DAA, foram observados melhores níveis de controle da aplicação aérea em relação à aplicação convencional (Figura 2). 
Na dose de $750 \mathrm{~g} \mathrm{ha}^{-1}$ (Figura 2), foram observados excelentes níveis de controle (> 95\%) de I. grandifolia e M. cissoides aos 75 e 110 DAA para aplicação líquida. Quando se utilizou os grânulos foram observados resultados inferiores de controle, porém podese observar pelos intervalos de confiança uma maior variação nos resultados. Carbonari et al.
(2010) observaram, em área de implantação de eucalipto, resultados de controle de plantas daninhas semelhantes ou superiores para aplicação aérea via grânulos de argila, sendo estes dependentes das espécies de planta daninha. Também foram observados ganhos no aumento do período residual deste herbicida.

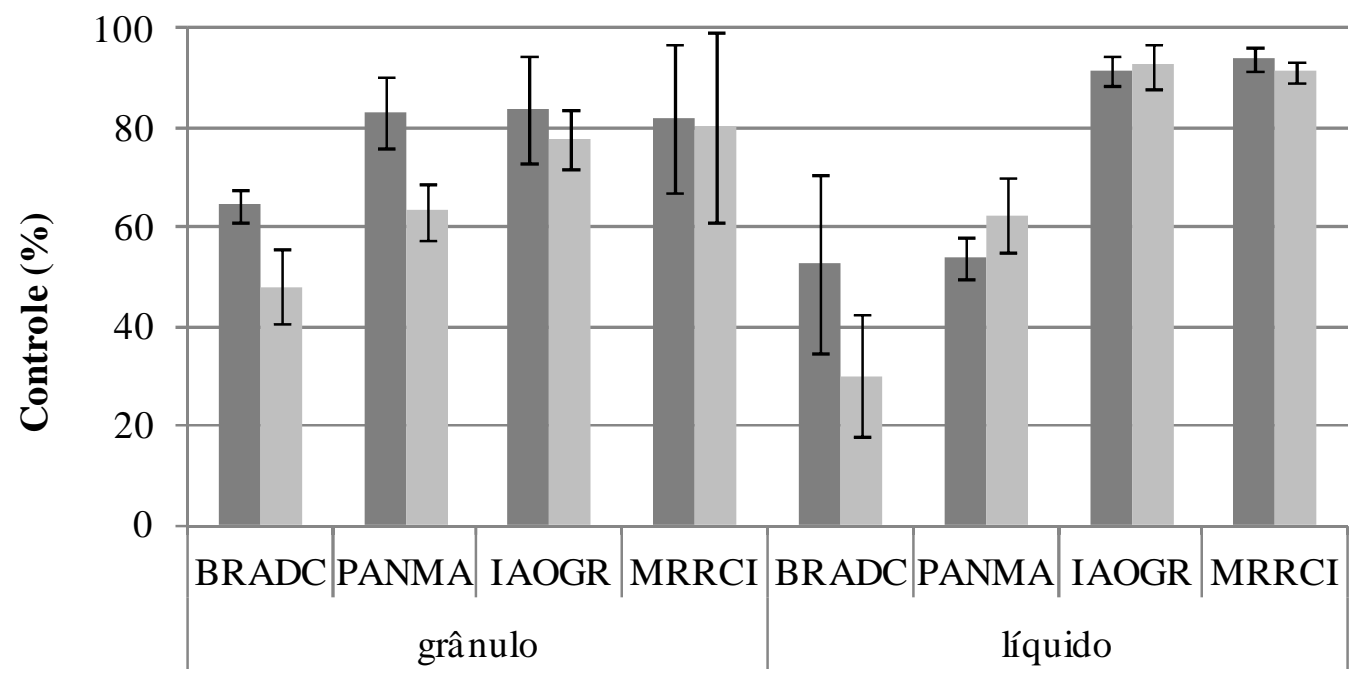

75 DAA $\square 110$ DAA

Figura 2. Controle de Brachiaria decumbens (BRADC), Panicum maximum (PANMA), Ipomoea grandifolia (IOAGR) e Merremia cissoides (MRRCI), pelo herbicida sulfentrazone na dose de $750 \mathrm{~g} \mathrm{ha}^{-1}$ aplicado via grânulos por avião e com calda liquida por pulverizador de barras em eucalipto aos 75 e 110 DAA. Capão Bonito/SP - 2007.

Observa-se nas Figuras 3 e 4, o controle das plantas daninhas para o isoxaflutole aos 75 e 110 DAA, nas doses de 150 e $225 \mathrm{~g} \mathrm{ha}^{-1}$, para as duas modalidades de aplicação testadas. Para o isoxaflutole, na dose de $150 \mathrm{~g} \mathrm{ha}^{-1}$, foram observados níveis insatisfatórios de controle, independente das diferentes espécies de plantas daninhas, para as duas modalidade de aplicação (Figuras 3). 


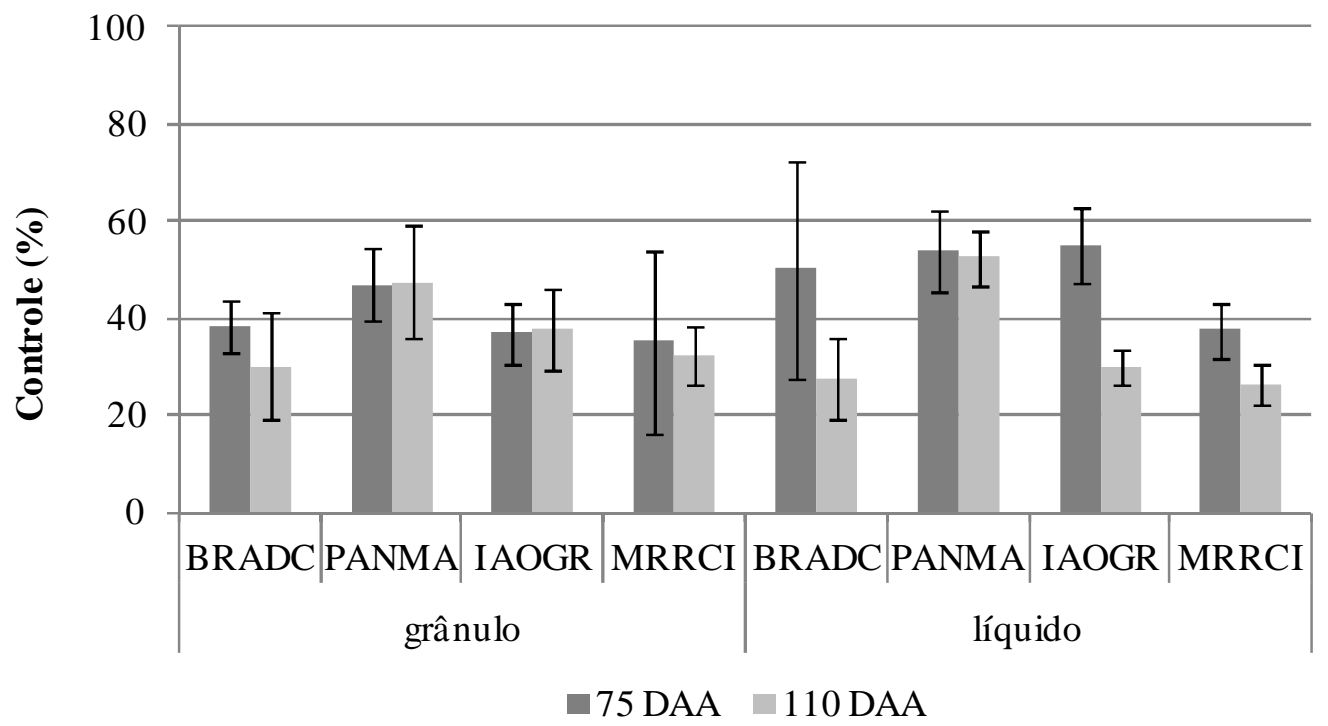

Figura 3. Controle de Brachiaria decumbens (BRADC), Panicum maximum (PANMA), Ipomoea grandifolia (IOAGR) e Merremia cissoides (MRRCI), pelo herbicida isoxaflutole a ou $150 \mathrm{~g} \mathrm{ha}^{-1}$ aplicado via grânulos por avião e com calda liquida por pulverizador de barras em eucalipto aos 75 e 110 DAA. Capão Bonito/SP - 2007.

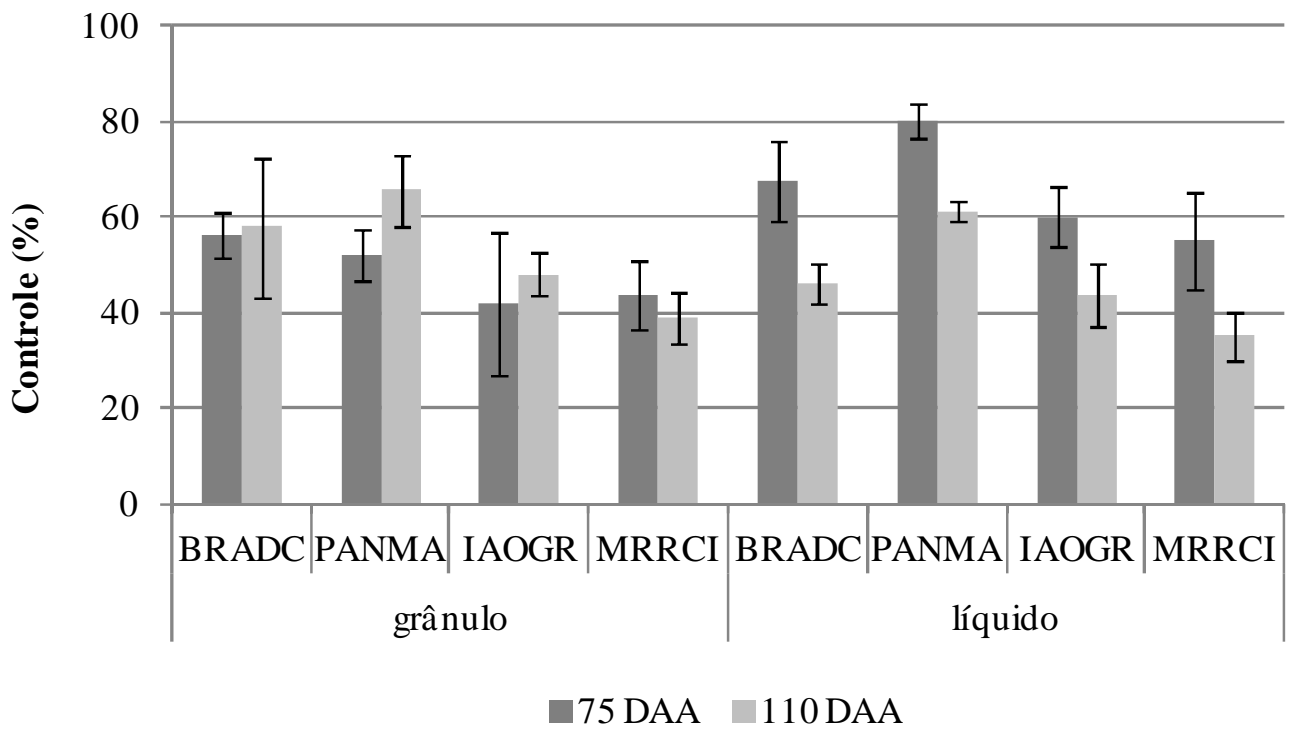

Figura 4. Controle de Brachiaria decumbens (BRADC), Panicum maximum (PANMA), Ipomoea grandifolia (IOAGR) e Merremia cissoides (MRRCI), pelo herbicida isoxaflutole na dose de $225 \mathrm{~g} \mathrm{ha}^{-1}$ aplicado via grânulos por avião e com calda liquida por pulverizador de barras em eucalipto aos 75 e 110 DAA. Capão Bonito/SP - 2007. 
Na dose de $225 \mathrm{~g} \mathrm{ha}^{-1}$, verificou-se para $B$. decumbens, $P$. maximum, I. grandifolia e $M$. cissoides aos 75 DAA, níveis inferiores de controle para aplicação aérea em relação à aplicação convencional (Figura 4). No entanto, aos 110 DAA foram observados níveis similares de controle entre as modalidades de aplicação para $B$. decumbens, I. grandifolia e $M$. cissoides. Para o P. maximum, pode-se observar controle superior para aplicação convencional com calda líquida. Tais resultados indicam que a quantidade de produto liberada nos primeiros 75 DAA foram inferiores aos da aplicação convencional, devido à necessidade de chuvas. Possivelmente, aos 110 DAA, quantidades significativas de isoxaflutole foram liberadas, permitindo níveis similares ou superiores aos da aplicação convencional.

Assim, verificou-se que se a liberação do isoxaflutole ocorre de forma mais lenta do grânulo de argila para o solo, o que pode permitir um maior efeito residual do produto no solo. Carbonari et al. (2010) obtiveram resultados mais concretos em relação ao controle das espécies $B$. decumbens e $P$. maximum com o isoxaflutole, para a aplicação aérea com o uso de grânulos de argila em relação à aplicação convencional com calda líquida e pulverizadores de barra.

\section{Conclusão}

Os melhores resultados foram observados para o sulfentrazone e isoxaflutole aplicados nas doses de 750 e $225 \mathrm{~g} \mathrm{ha}^{-1}$, respectivamente. Para $500 \mathrm{~g} \mathrm{ha}^{-1} \mathrm{de}$ sulfentrazone observou-se níveis similares de controle de todas as espécies testadas para as duas modalidades de aplicação.

$\mathrm{Na}$ dose de $750 \mathrm{~g} \mathrm{ha}^{-1}$ verificou-se melhores resultados das espécies $B$. decumbens e $P$. maximum para aplicação com grânulos em relação à convencional e níveis similares para as demais espécies de plantas daninhas.
O isoxaflutole na dose de $150 \mathrm{~g} \mathrm{ha}^{-1}$, apresentou níveis insatisfatórios de controle, nas duas modalidades de aplicação. Na dose de $225 \mathrm{~g} \mathrm{ha}^{-1}$ observou-se inicialmente resultados melhores para aplicação convencional e ao final do experimento, níveis maiores ou similares para aplicação na formulação sólida, em relação à aplicação convencional.

\section{Referências}

AGOSTINETTO, D. et al. Seletividade de genótipos de eucalipto a doses de herbicidas. Semina: Ciências Agrárias, v.31, n.3, p.585598, 2010.

ABRAF. Anuário estatístico da ABRAF 2011: Ano base 2010. ABRAF: Brasília, 2011.125p.

CARBONARI, C.A. et al. Eficácia da utilização de grânulos de argila como veículo para a aplicação aérea de sulfentrazone e isoxaflutole em área de implantação de eucalipto. Planta Daninha, v.28, n.1, p207212, 2010 .

FMC do Brasil Ltda. Manual de produtos. Campinas, 1997. p. 77.

OLIVETTE, M.P.A. et al. Evolução e prospecção da agricultura paulista: liberação da área de pastagem para o cultivo da cana-deaçúcar, eucalipto, seringueira e reflexos na pecuária, Informações Econômicas, v.41, n.3, p.37-67, 2011.

MORA, A.L.; GARCIA, C.H. A Cultura do Eucalipto no Brasil. Sociedade Brasileira de Silvicultura: São Paulo, 2000.

RODRIGUES, B.N.; ALMEIDA, F.S. Guia de herbicidas. 5.ed. Londrina: Edição dos Autores, 2005. p.592.

SBCPD. Procedimentos para instalação, avaliação e análise de experimentos com herbicidas. Londrina: SBCPD, 1995. 42 p. 
TUFFI SANTOS, L.D. et al. Intoxicação de Eucalipto Submetido à Deriva Simulada de Diferentes Herbicidas. Planta Daninha, v.24, n.3, p.521-526, 2006.

TURNBULL, C.R.A. et al. Effect of postplanting applications of granulated atrazine and fertiliser on the early growth of Eucalyptus nitens. New Forests, v.8, n.4, p.323-333, 1994. 